\title{
Prone Position for Acute Respiratory Distress Syndrome A Systematic Review and Meta-Analysis
}

\author{
Laveena Munshi ${ }^{1}$, Lorenzo Del Sorbo ${ }^{1}$, Neill K. J. Adhikari ${ }^{2}$, Carol L. Hodgson ${ }^{3}$, Hannah Wunsch ${ }^{4}$, Maureen O. Meade ${ }^{5}$, \\ Elizabeth Uleryk $^{6}$, Jordi Mancebo ${ }^{7}$, Antonio Pesenti ${ }^{8}$, V. Marco Ranieri ${ }^{9}$, and Eddy Fan ${ }^{1}$ \\ ${ }^{1}$ Interdepartmental Division of Critical Care Medicine, Toronto General Hospital, Toronto, Ontario, Canada; ${ }^{2}$ Sunnybrook Health Sciences \\ Centre, Toronto, Ontario, Canada; ${ }^{3}$ Monash University, Melbourne, Victoria, Australia; ${ }^{4}$ Critical Care Medicine, University of Toronto, \\ Toronto, Ontario, Canada; ${ }^{5}$ McMaster University, Hamilton, Ontario, Canada; ${ }^{6}$ Hospital for Sick Children, Toronto, Ontario, \\ Canada; ${ }^{7}$ University of Montreal, Montreal, Quebec, Canada; ${ }^{8}$ Universita degli Studi di Milano, Milan, Italy; and ${ }^{9}$ Policlinico Umberto I, \\ Università "La Sapienza" Roma, Rome, Italy
}

\section{Abstract}

Rationale: The application of prone positioning for acute respiratory distress syndrome (ARDS) has evolved, with recent trials focusing on patients with more severe ARDS, and applying prone ventilation for more prolonged periods.

Objectives: This review evaluates the effect of prone positioning on 28-day mortality (primary outcome) compared with conventional mechanical ventilation in the supine position for adults with ARDS.

Methods: We updated the literature search from a systematic review published in 2010, searching MEDLINE, EMBASE, and CENTRAL (through to August 2016). We included randomized, controlled trials (RCTs) comparing prone to supine positioning in mechanically ventilated adults with ARDS, and conducted sensitivity analyses to explore the effects of duration of prone ventilation, concurrent lung-protective ventilation and ARDS severity. Secondary outcomes included $\mathrm{Pa}_{\mathrm{O}_{2}} / \mathrm{FI}_{\mathrm{O}_{2}}$ ratio on Day 4 and an evaluation of adverse events. Meta-analyses used random effects models. Methodologic quality of the RCTs was evaluated using the Cochrane risk of bias instrument, and methodologic quality of the overall body of evidence was evaluated using the GRADE (Grading of Recommendations Assessment, Development, and Evaluation) guidelines.

Results: Eight RCTs fulfilled entry criteria, and included 2,129 patients (1,093 [51\%] proned). Meta-analysis revealed no difference in mortality (risk ratio [RR], 0.84 ; 95\% confidence interval [CI], 0.681.04), but subgroup analyses found lower mortality with 12 hours or greater duration prone (five trials; RR, 0.74; 95\% CI, 0.56-0.99) and for patients with moderate to severe ARDS (five trials; RR, 0.74; 95\% CI, 0.56-0.99). $\mathrm{Pa}_{\mathrm{O}_{2}} / \mathrm{FI}_{\mathrm{O}_{2}}$ ratio on Day 4 for all patients was significantly higher in the prone positioning group (mean difference, 23.5; 95\% CI, 12.4-34.5). Prone positioning was associated with higher rates of endotracheal tube obstruction and pressure sores. Risk of bias was low across the trials.

Conclusions: Prone positioning is likely to reduce mortality among patients with severe ARDS when applied for at least 12 hours daily.

Keywords: critical care; prone position; intensive care units; adult respiratory distress syndrome; systematic review

(Received in original form April 26, 2017; accepted in final form August 15, 2017)

Author Contributions: L.M.: Idea generation, methodology, review of search results, statistical analysis, and manuscript preparation; L.D.S.: methodology, database management, review of search results, statistical analysis, and manuscript review; N.K.J.A., C.L.H., H.W., and M.O.M.: methodology, statistical analysis support, and manuscript review; E.U.: search strategy development, conducted search, and manuscript review; J.M., A.P., and V.M.R.: idea generation, results review, and manuscript review; E.F.: project oversight, idea generation, methodology, and manuscript preparation and feedback.

Correspondence and requests for reprints should be addressed to Eddy Fan, M.D., Ph.D., University of Toronto, Interdepartmental Division of Critical Care Medicine, Toronto General Hospital, 585 University Avenue, Toronto, ON, 11C-1167 Canada. E-mail: eddy.fan@uhn.ca

This article has an online supplement, which is accessible from this issue's table of contents at www.atsjournals.org

Ann Am Thorac Soc Vol 14, Supplement 4, pp S280-S288, Oct 2017

Copyright @ 2017 by the American Thoracic Society

DOI: 10.1513/AnnalsATS.201704-3430T

Internet address: www.atsjournals.org

Mechanical ventilation in the prone position, first reported in 1970 (1), has been evaluated as a strategy to enhance oxygenation and lung recruitment in acute respiratory failure. The mechanisms by which prone positioning may benefit patients with acute respiratory distress syndrome (ARDS) undergoing mechanical ventilation include improving ventilationperfusion matching (2), increasing endexpiratory lung volume (3), and preventing ventilator-induced lung injury by more uniform distribution of tidal volume through lung recruitment and alterations in chest wall mechanics. Early trials persistently demonstrated improved oxygenation (4-6). Although these trials did not demonstrate a mortality benefit from prone positioning, post hoc analysis of subgroups with more severe forms for respiratory failure suggested benefit (7). 
With a better understanding of the appropriate target population, more recent randomized trials attempted to address this question with modern prone positioning protocols, demonstrating promising results.

To inform the section on prone positioning for the American Thoracic Society/European Society of Intensive Care Medicine/Society of Critical Care Medicine Clinical Practice Guideline: Mechanical Ventilation in Adult Patients with Acute Respiratory Distress Syndrome, this analysis aimed to determine the effect on mortality (primary outcome) in adults with ARDS in the prone position versus ventilation exclusively in the supine position.

\section{Methods}

\section{Search Strategy}

We identified the most recent systematic reviews of prone positioning in patients with ARDS and performed an updated systematic review to identify subsequent relevant trials (see Appendix E1 in the online supplement) $(7,8)$. A professional librarian (E.U.) ran a search on the OvidSP search platform in the MEDLINE and EMBASE databases and the Wiley search platform in the Cochrane Central Register of Controlled Trials. We used both subject headings and text-word terms to search for articles on ARDS, prone positioning, and adults (Cochrane, McMaster, Robinson Dickersin clinical trials filters) (Appendix E2). The results were limited to the publication years 2009 to articles indexed as of August 8, 2016. We retrieved a total of 2,121 references. All references were saved in an EndNote (Philadelphia, PA) library used to identify the 373 duplicates. The remaining 1,748 unique references were reviewed against our inclusion criteria. There were no language restrictions.

\section{Study Inclusion Criteria}

Two reviewers (L.M. and L.D.S.) independently reviewed all citations for inclusion and extracted potentially relevant studies for full-text review. Both reviewers also independently reviewed the full text of potentially relevant studies and decided on eligibility. Any disagreements were resolved by consensus with a third reviewer (E.F.). We included randomized, controlled trials (RCTs) that compared mechanical ventilation in the prone position to ventilation in the supine position in adults with ARDS and reported mortality (7). Given the recent update in
ARDS criteria, any trials that enrolled patients who, in hindsight, met the more recently defined Berlin criteria for ARDS were included (9).

\section{Data Extraction and Study Quality}

A customized Excel (Microsoft Corporation, Redmond, WA) spreadsheet was used to store independently abstracted data on study design, patient characteristics, interventions, and study outcomes. All studies were assessed for evidence of bias using the Cochrane Collaboration risk of bias instrument, including assessment for random sequence generation, allocation concealment, blinding of caregivers, and outcome assessment, incomplete outcome data and selective reporting and the use of important cointerventions (10). We considered a study's overall risk of bias to be high if any domain was judged to be at high risk of bias, with the exception of caregiver blinding, for which we accepted standardization of mechanical ventilation (while supine), sedation, and weaning in both study arms to mitigate performance bias in these necessarily unblinded trials. The GRADE (Grading of Recommendations Assessment, Development, and Evaluation) guidelines were used for rating the quality of evidence (11). Summary of Findings tables were prepared using GRADEpro software (McMaster University, Hamilton, ON, Canada, 2014) (12).

\section{Outcomes}

We analyzed the following outcomes in our analysis, based on consensus among the content experts in our group regarding critical and important outcomes. Our primary outcome was mortality within 28 days, or, if not available, then mortality within 30 days in hospital or intensive care (in that sequence). Secondary outcomes included 90-day mortality, 6-month mortality, absolute $\mathrm{Pa}_{\mathrm{O}_{2}} / \mathrm{FI}_{\mathrm{O}_{2}}$ ratio on Day 4 , and adverse events (unplanned central catheter removal, unplanned extubation, endotracheal tube obstruction, ventilatorassociated pneumonia, and pressure sores).

\section{Statistical Analysis}

We reported dichotomous outcomes using risk ratio (RR) and continuous outcomes using mean difference, with $95 \%$ confidence intervals (CIs). For each analysis, studies were weighted using the inverse variance method, and data were pooled using a random effects model (13). We assessed clinical heterogeneity among studies qualitatively, and statistical heterogeneity using the $I^{2}$ measure (14) A $P$ value of 0.05 or less was considered to be statistically significant.

A series of a priori-determined subgroup analyses were performed for studies using lung-protective ventilation (defined as tidal volume $\leqslant 8 \mathrm{ml} / \mathrm{kg}$ predicted body weight) (15) compared with those without lung-protective ventilation, duration of prone position ( $\geqslant 12 \mathrm{~h}$ compared with $<12 \mathrm{~h}$ ), and severity of ARDS (trials enrolling patients with moderate to severe ARDS versus those enrolling patients with any level of severity). These subgroups were selected given their likelihood to reflect the population and application of prone positioning in current practice; furthermore, this approach/population may reflect the subgroup in which it may be the most beneficial. Mild ARDS was considered a $\mathrm{Pa}_{\mathrm{O}_{2}} / \mathrm{FI}_{\mathrm{O}_{2}}$ of $201-300 \mathrm{~mm} \mathrm{Hg}$, moderate was considered a $\mathrm{Pa}_{\mathrm{O}_{2}} / \mathrm{FI}_{\mathrm{O}_{2}}$ of $101-200 \mathrm{~mm} \mathrm{Hg}$, and severe was considered a $\mathrm{Pa}_{\mathrm{O}_{2}} / \mathrm{FI}_{\mathrm{O}_{2}}$ of less than $100 \mathrm{~mm} \mathrm{Hg}$ (9). All categorization for severity of ARDS was based upon $\mathrm{Pa}_{\mathrm{O}_{2}} / \mathrm{FI}_{\mathrm{O}_{2}}$ at randomization. For the latter analysis, we also used within-trial subgroup data of $\mathrm{Pa}_{\mathrm{O}_{2}} / \mathrm{FI}_{\mathrm{O}_{2}}$ ratio, as previously published (7). In a post hoc analysis to evaluate the potential collinearity that may exist between the use of lung-protective ventilation and duration of time prone, a subgroup analysis of duration of time prone (long vs. short) was isolated to studies that just employed lung-protective ventilation. This analysis was repeated in studies that did not employ lung-protective ventilation.

To assess publication bias, we visually examined funnel plots of treatment effect versus study precision. All statistical analyses were performed using RevMan 5.2 (Cochrane Collaboration, Oxford, UK).

\section{Results}

The most recent systematic reviews identified before this study were by Sud and colleagues (7) and Abroug and colleagues (8). The updated electronic search revealed 1,748 citations, of which 1 additional trial met inclusion criteria (Appendix E3). We excluded three trials included in the review by Sud and colleagues, given that they did not fulfill our inclusion criteria (16-18). One study had a minimal focus on ARDS (16), one study was a pediatric study (17), and one study did not provide mortality data (18). 


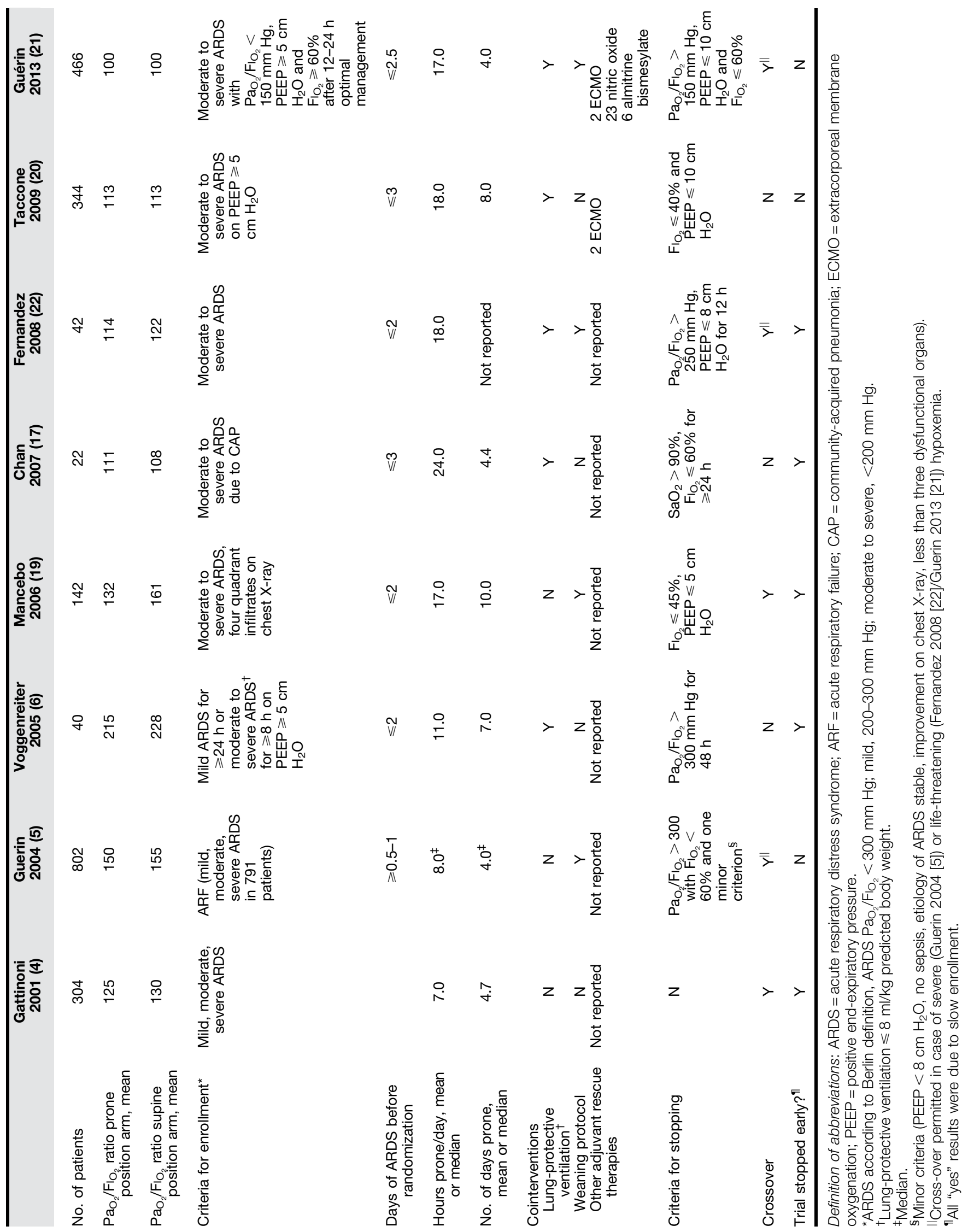


Table 2. Risk of bias (mortality outcome)

\begin{tabular}{|c|c|c|c|c|c|c|}
\hline $\begin{array}{l}\text { Study } \\
\text { (Reference) }\end{array}$ & $\begin{array}{c}\text { Random } \\
\text { Sequence } \\
\text { Generation } \\
\text { (Selection Bias) }\end{array}$ & $\begin{array}{c}\text { Allocation } \\
\text { Concealment } \\
\text { (Selection Bias) }\end{array}$ & $\begin{array}{c}\text { Blinding of } \\
\text { Participants } \\
\text { and Personnel } \\
\text { (Performance Bias) }\end{array}$ & $\begin{array}{c}\text { Blinding of } \\
\text { Outcome } \\
\text { Assessment } \\
\text { (Detection Bias) }\end{array}$ & $\begin{array}{l}\text { Incomplete } \\
\text { Outcome Data } \\
\text { (Attrition Bias) }\end{array}$ & $\begin{array}{c}\text { Selective } \\
\text { Reporting } \\
\text { (Reporting } \\
\text { Bias) }\end{array}$ \\
\hline Gattinoni et al. 2001 (4) & + & + & - & + & + & + \\
\hline Guerin et al. 2004 (5) & + & + & - & + & + & + \\
\hline Voggenreiter et al. 2005 (6) & + & + & - & + & + & + \\
\hline Mancebo et al. 2006 (19) & + & + & - & $?$ & + & + \\
\hline Chan et al. 2007 (23) & + & - & - & $?$ & + & + \\
\hline Fernandez et al. 2008 (22) & + & + & - & + & + & + \\
\hline Taccone et al. 2009 (20) & + & + & - & + & + & + \\
\hline Guérin et al. 2013 (21) & + & + & - & + & + & + \\
\hline
\end{tabular}

$+=$ risk of bias is low; $-=$ risk of bias is high; ? = unknown risk of bias.

Eight RCTs met our inclusion criteria, with a total of 2,129 patients (1,093 prone) with ARDS and an overall median (interquartile range) mortality rate of $45.0 \%$ (27.5-49.5\%) among those ventilated in the prone position. Study characteristics are summarized in Table 1. More recent studies enrolled patients with more severe ARDS (19-22), mandated a longer duration of time prone (19-22), mandated lungprotective ventilation in both arms $(6,20-23)$, and mandated a lower threshold for stopping prone positioning (i.e., higher severity of illness in course of ARDS, at which point prone positioning was terminated-see Table 1) $(21,22)$. A significant proportion (63\%) of initial studies was terminated early due to slow

Table 3. Summary of findings: ventilation in the prone position compared to supine position for ARDS

\begin{tabular}{|c|c|c|c|c|c|}
\hline \multirow[t]{2}{*}{ Outcomes } & \multicolumn{2}{|c|}{ Illustrative Comparative Risks* $(95 \%$ Cl) } & \multirow[t]{2}{*}{ RR (95\% Cl) } & \multirow{2}{*}{$\begin{array}{l}\text { No. of } \\
\text { Participants } \\
\text { (Studies) }\end{array}$} & \multirow{2}{*}{$\begin{array}{l}\text { Quality of the } \\
\text { Evidence } \\
\text { (GRADE) }\end{array}$} \\
\hline & $\begin{array}{l}\text { Assumed Risk } \\
\text { Supine for ARDS }\end{array}$ & $\begin{array}{c}\text { Corresponding Risk } \\
\text { Prone }\end{array}$ & & & \\
\hline $\begin{array}{l}\text { Mortality } \\
\text { Study population } \\
\text { Moderate }\end{array}$ & $\begin{array}{l}374 \text { per } 1,000 \\
348 \text { per } 1,000\end{array}$ & $\begin{array}{l}310 \text { per } 1,000(250-388) \\
289 \text { per } 1,000(233-362)\end{array}$ & $0.84(0.68-1.04)$ & 2,129 (8 studies) & $\oplus \oplus \oplus \ominus$ Moderate ${ }^{\dagger}$ \\
\hline $\begin{array}{l}\text { Mortality, lung-protective } \\
\text { ventilation studies } \\
\text { Study population } \\
\text { Moderate }\end{array}$ & $\begin{array}{l}331 \text { per } 1,000 \\
331 \text { per } 1,000\end{array}$ & $\begin{array}{l}232 \text { per } 1,000(156-344) \\
232 \text { per } 1,000(156-344)\end{array}$ & $0.70(0.47-1.04)$ & 906 (5 studies) & $\oplus \oplus \oplus \ominus$ Moderate \\
\hline $\begin{array}{l}\text { Mortality, prolonged } \\
\text { duration prone } \geqslant 12 \mathrm{~h} \\
\text { Study population } \\
\text { Moderate }\end{array}$ & $\begin{array}{l}373 \text { per } 1,000 \\
364 \text { per } 1,000\end{array}$ & $\begin{array}{l}276 \text { per } 1,000(209-369) \\
269 \text { per } 1,000(204-360)\end{array}$ & $0.74(0.56-0.99)$ & 1,002 (5 studies) & $\oplus \oplus \oplus \oplus$ High \\
\hline $\begin{array}{l}\text { Mortality, moderate to } \\
\text { severe ARDS studies } \\
\text { Study population } \\
\text { Moderate }\end{array}$ & $\begin{array}{l}371 \text { per } 1,000 \\
364 \text { per } 1,000\end{array}$ & $\begin{array}{l}275 \text { per } 1,000(208-367) \\
269 \text { per } 1,000(204-360)\end{array}$ & $0.74(0.56-0.99)$ & 1,006 (5 studies) & $\oplus \oplus \oplus \ominus$ Moderate $^{\dagger}$ \\
\hline $\begin{array}{l}\text { Pressure sores } \\
\text { Study population } \\
\text { Moderate }\end{array}$ & $\begin{array}{l}345 \text { per } 1,000 \\
188 \text { per } 1,000\end{array}$ & $\begin{array}{l}420 \text { per } 1,000(365-486) \\
229 \text { per } 1,000(199-265)\end{array}$ & $1.22(1.06-1.41)$ & 1,109 (3 studies) & $\oplus \oplus \oplus \oplus$ High \\
\hline $\begin{array}{l}\text { Endotracheal tube } \\
\text { obstruction } \\
\text { Study population } \\
\text { Moderate }\end{array}$ & $\begin{array}{l}98 \text { per } 1,000 \\
32 \text { per } 1,000\end{array}$ & $\begin{array}{l}172 \text { per } 1,000(121-244) \\
56 \text { per } 1,000(40-80)\end{array}$ & $1.76(1.24-2.5)$ & 1,594 (3 studies) & $\oplus \oplus \oplus \ominus$ Moderate ${ }^{\dagger}$ \\
\hline
\end{tabular}

Definition of abbreviations: ARDS = acute respiratory distress syndrome; $\mathrm{Cl}=$ confidence interval; GRADE = Grading of Recommendations Assessment, Development, and Evaluation; $\mathrm{RR}=$ risk ratio.

Patient or population: patients with acute respiratory distress syndrome; intervention: ventilation in prone position; comparison: ventilation in supine position. GRADE Working Group grades of evidence: high quality - further research is very unlikely to change our confidence in the estimate of effect; moderate quality - further research is likely to have an important impact on our confidence in the estimate of effect and may change the estimate; low quality- further research is very likely to have an important impact on our confidence in the estimate of effect and is likely to change the estimate; very low quality - we are very uncertain about the estimate. $\oplus$ symbols indicate the number of GRADE criteria (out of 4) that were satisfied; $\ominus$ symbols indicate the number of GRADE criteria that were not satisfied.

*The basis for the assumed risk (e.g., the median control group risk across studies) is provided in footnotes. The corresponding risk (and its $95 \% \mathrm{Cl}$ ) is based on the assumed risk in the comparison group and the relative effect of the intervention (and its $95 \% \mathrm{Cl}$ ).

†Optimal informal size insufficient.

FWide Cls. 
Favors Prone Favors Supine

\begin{tabular}{|c|c|c|c|c|c|c|}
\hline \multirow[b]{2}{*}{ Study or Subgroup } & & & \multirow[b]{2}{*}{ Weight } & \multirow{2}{*}{ IV, Random, $95 \% \mathrm{CI}$} \\
\hline & Events & Total & Events & Total & & \\
\hline Gattinoni et al. 2001 & 70 & 152 & 67 & 152 & $19.1 \%$ & $1.04[0.82,1.34]$ \\
\hline Guerin et al. 2004 & 134 & 413 & 119 & 378 & $20.9 \%$ & $1.03[0.84,1.26]$ \\
\hline Voggenreiter et al. 2005 & 1 & 21 & 3 & 19 & $0.9 \%$ & $0.30[0.03,2.66]$ \\
\hline Mancebo et al. 2006 & 38 & 76 & 37 & 60 & $17.0 \%$ & $0.81[0.60,1.10]$ \\
\hline Chan et al. 2007 & 4 & 11 & 4 & 11 & $3.2 \%$ & $1.00[0.33,3.02]$ \\
\hline Fernandez et al. 2008 & 8 & 21 & 10 & 19 & $6.9 \%$ & $0.72[0.36,1.45]$ \\
\hline Taccone et al. 2009 & 52 & 168 & 57 & 174 & $16.6 \%$ & $0.94[0.69,1.29]$ \\
\hline Guerin et al. 2013 & 38 & 237 & 75 & 229 & $15.3 \%$ & $0.49[0.35,0.69]$ \\
\hline Total $(95 \% \mathrm{Cl})$ & & 1099 & & 1042 & $100.0 \%$ & $0.84[0.68,1.04]$ \\
\hline Total events & 345 & & 372 & & & \\
\hline
\end{tabular}

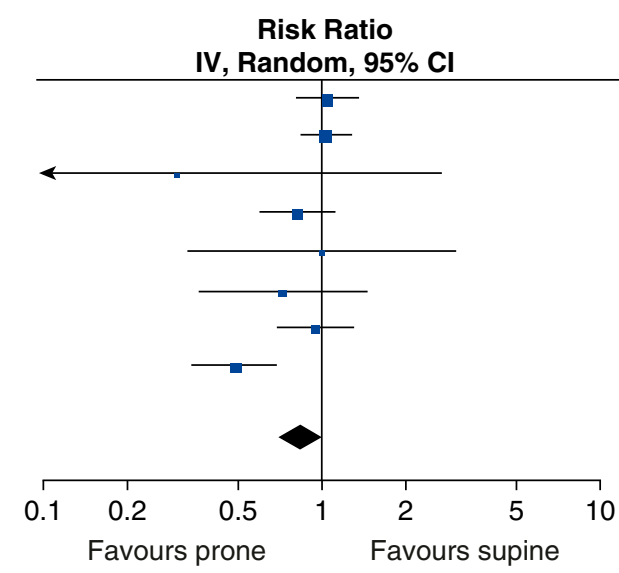

Figure 1. Primary outcome: mortality. Forest plot demonstrating pooled data of early mortality across all randomized trials using a random effects model. Early mortality was defined as 28-day mortality used for all studies where available; for Gattinoni and colleagues (4), 30-day mortality was used, for Voggenreiter and colleagues (6), 90-day mortality was used, for Fernandez and colleagues (22), 60-day mortality was used, and for Mancebo and colleagues (19), in-hospital mortality was used. The arrowhead indicates that the lower confidence interval is beyond the $x$-axis of the graph. $\mathrm{Cl}=$ confidence interval; $\mathrm{df}=$ degrees of freedom; Events = number of deaths; $l^{2}=$ statistical heterogeneity; IV = inverse variance; Total = total number of patients

enrolment $(4,6,19,22,23)$. Risk of bias for our primary outcome was low across all studies with the exception of one (23), and is summarized in Table 2. Visual inspection of a funnel plot did not suggest publication bias (Appendix E6).
All results presented subsequently here are summarized in Table 3.

\section{Mortality}

Four studies reported 28-day mortality $(5,20,21,23)$, whereas one study provided data on 30-day mortality (4), one on in-hospital mortality (19), one on 60-day mortality (22), and one on 90-day mortality (6). Meta-analysis did not detect a significant difference in mortality between prone and supine positioning $(\mathrm{RR}, 0.84$;

\begin{tabular}{|c|c|c|c|c|c|c|}
\hline \multirow[b]{2}{*}{ Study or Subgroup } & \multicolumn{2}{|c|}{ Prone } & \multicolumn{2}{|c|}{ Supine } & \multirow[b]{2}{*}{ Weight } & \multirow{2}{*}{$\begin{array}{c}\text { Risk Ratio } \\
\text { IV, Random, } 95 \% \text { C }\end{array}$} \\
\hline & Events & Total & Events & Total & & \\
\hline \multicolumn{7}{|c|}{ Lung Protective Ventilation Studies } \\
\hline Voggenreiter et al. 2005 & 1 & 21 & 3 & 19 & $3.1 \%$ & $0.30[0.03,2.66]$ \\
\hline Chan et al. 2007 & 4 & 11 & 4 & 11 & $9.9 \%$ & $1.00[0.33,3.02]$ \\
\hline Fernandez et al. 2008 & 8 & 21 & 10 & 19 & $18.8 \%$ & $0.72[0.36,1.45]$ \\
\hline Taccone et al. 2009 & 52 & 166 & 57 & 172 & $35.0 \%$ & $0.95[0.69,1.29]$ \\
\hline Guerin et al. 2013 & 38 & 237 & 75 & 229 & $33.3 \%$ & $0.49[0.35,0.69]$ \\
\hline Subtotal $(95 \% \mathrm{Cl})$ & & 456 & & 450 & $100.0 \%$ & $0.70[0.47,1.04]$ \\
\hline $\begin{array}{l}\text { Total events } \\
\text { Heterogeneity: } \mathrm{Tau}^{2}=0 \\
\text { Test for overall effect: } Z\end{array}$ & $\begin{array}{r}103 \\
0.09 ; \mathrm{Chi} \\
\mathrm{Z}=1.76(\end{array}$ & $\begin{array}{r}8.70, \\
=0.08\end{array}$ & $\begin{array}{c}149 \\
d f=4(P\end{array}$ & $=0$. & $\%$ & \\
\hline \multicolumn{7}{|c|}{ Non-Lung Protective Ventilation Studies } \\
\hline Gattinoni et al. 2001 & 70 & 152 & 67 & 152 & $31.6 \%$ & $1.04[0.82,1.34]$ \\
\hline Guerin et al. 2004 & 134 & 413 & 119 & 378 & $46.8 \%$ & $1.03[0.84,1.26]$ \\
\hline Mancebo et al. 2006 & 38 & 76 & 37 & 60 & $21.6 \%$ & $0.81[0.60,1.10]$ \\
\hline Subtotal $(95 \% \mathrm{Cl})$ & & 641 & & 590 & $100.0 \%$ & $0.98[0.85,1.13]$ \\
\hline $\begin{array}{l}\text { Total events } \\
\text { Heterogeneity: } \text { Tau }^{2} \\
\text { Test for overall effect }\end{array}$ & $\begin{array}{r}242 \\
.00 ; \mathrm{Chi} \\
=0.24(\end{array}$ & 0 & $\begin{aligned} & 223 \\
= & 2(P\end{aligned}$ & -0.4 & $\%$ & \\
\hline
\end{tabular}

Test for subgroup differences: $\mathrm{Chi}^{2}=2.50, \mathrm{df}=1(\mathrm{P}=0.11), l^{2}=60.0 \%$

Figure 2. Primary outcome: mortality; sensitivity analysis: studies, including lung-protective ventilation. Forest plot demonstrating pooled data of early mortality in studies employing lung-protective ventilation versus those without lung-protective ventilation using a random effects model. Early mortality was defined as 28 -day mortality used for all studies where available; for Gattinoni and colleagues (4), 30-day mortality was used, for Voggenreiter and colleagues (6), 90-day mortality was used, for Fernandez and colleagues (22), 60-day mortality was used, and for Mancebo and colleagues (19), in-hospital mortality was used. The arrowhead indicates that the lower confidence interval is beyond the $x$-axis of the graph. $\mathrm{Cl}=$ confidence interval; $\mathrm{df}=$ degrees of freedom; Events = number of deaths; $P=$ statistical heterogeneity; $\mathrm{N}=$ inverse variance; Total $=$ total number of patients. 


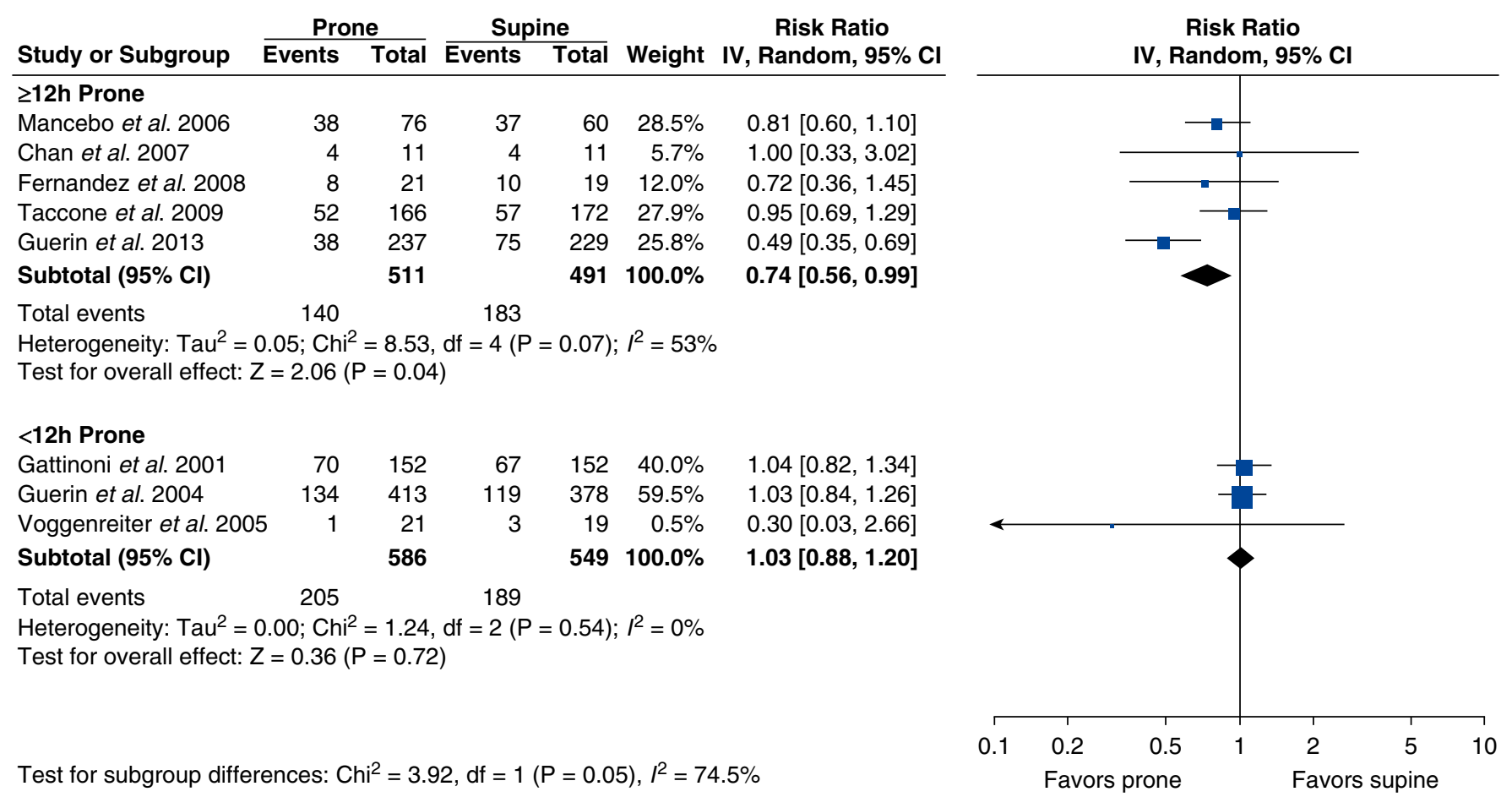

Figure 3. Primary outcome: mortality; subgroup analysis: duration of time prone. Forest plot demonstrating pooled data of early mortality in studies with a longer duration of time prone $(\geqslant 12 \mathrm{~h})$ versus a shorter time $(<12 \mathrm{~h})$ using a random effects model. Early mortality was defined as 28 -day mortality used for all studies where available; for Gattinoni and colleagues (4), 30-day mortality was used, for Voggenreiter and colleagues (6), 90-day mortality was used, for Fernandez and colleagues (22), 60-day mortality was used, and for Mancebo and colleagues (19), in-hospital mortality was used. The arrowhead indicates that the lower confidence interval is beyond the $x$-axis of the graph. $\mathrm{Cl}=$ confidence interval; $\mathrm{df}=\mathrm{degrees}$ of freedom; Events = number of deaths; $I^{2}=$ statistical heterogeneity; IV = inverse variance; Total = total number of patients.

95\% CI, 0.68-1.04; $I^{2}, 59 \%$; Figure 1). Similarly, a subgroup analysis limited to studies that applied lung-protective ventilation $(6,20-23)$ detected no significant reduction in mortality with lung protection (five trials; RR, 0.70; 95\% CI, $\left.0.47-1.04 ; I^{2}, 54 \%\right)$, and the test for subgroup effect was not statistically significant $(P=0.11)$ (Figure 2$)$.

The impact of the duration of prone positioning was evaluated comparing studies of longer versus shorter durations of prone positioning. Mortality was reduced in the five trials (18-23) in which patients were proned for 12 hours or longer daily (RR, $0.74 ; 95 \%$ CI, 0.56-0.99; $I^{2}, 53 \%$ ) compared with three trials that proned patients for less than 12 hours daily (RR, 1.03; 95\% CI, 0.88-1.20; $I^{2}$, $0 \%$; $P$ for subgroup difference, 0.05 ; Figure 3 ).

Finally, mortality was stratified by study-level severity of ARDS inclusion criteria according to the Berlin definition (all ARDS vs. only moderate to severe ARDS), and a mortality difference favoring moderate to severe ARDS studies was noted (RR, 0.74; 95\% CI, 0.54-0.99; $I^{2}, 53 \%$; all ARDS: RR, 1.03 ; 95\% CI, $0.88-1.20 ; I^{2}, 0 \%$;
$P$ for subgroup differences, 0.05; Figure 4). The impact of prone positioning on mortality based upon severity of ARDS was also analyzed using published subgroup data (7) obtained from each study (severe: RR, 0.82 ; $95 \%$ CI, $0.72-0.93 ; I^{2}, 0 \%$; mild to moderate: RR, 0.90; 95\% CI, 0.68-1.17; $I^{2}, 65 \%$; Appendix E4; $P$ for subgroup difference, 0.57). Of note, in the latter analysis, the mortality time points were obtained from the last known follow-up time, and there were no "mild" $\left(\mathrm{Pa}_{\mathrm{O}_{2}} / \mathrm{FI}_{\mathrm{O}_{2}}\right.$ 200-300) cases of ARDS in five of the studies (19-23).

Given that the predominant studies driving the non-lung-protective ventilation subgroup were also the studies that employed a shorter-duration prone position $(4,5)$, an exploratory post hoc analysis was performed in attempt to delineate the impact of duration of time prone independent of the effect of lung-protective ventilation (Appendix E5). These analyses, limited by the small numbers of studies in the comparator subgroups, did not demonstrate any difference in mortality between prone positioning and supine positioning.
There was moderate clinical and statistical heterogeneity noted for the pooled mortality outcome assessment across studies. The overall quality of evidence for our primary and secondary outcomes was graded as moderate to high (Table 3 ).

\section{Secondary Outcomes}

Meta-analyses for secondary outcomes, including 90-day mortality and 6-month mortality, did not demonstrate a difference between prone and supine positioning (Appendix E4). $\mathrm{Pa}_{\mathrm{O}_{2}} / \mathrm{FI}_{\mathrm{O}_{2}}$ ratio on Day 4 was significantly higher in the prone-positioning group compared with the supine position group (mean difference, 23.5; 95\% CI, 12.4$34.5 ; I^{2}, 24 \%$; Appendix E4).

\section{Adverse Events}

Four studies reported on barotrauma and ventilator-associated pneumonia $(5,19,22$, $23)$, three studies on unplanned central catheter removal during prone positioning $(4,20,23)$, and eight studies on unplanned extubation (4-6, 19-23). Meta-analyses showed no differences between prone positioning compared with supine 


\begin{tabular}{|c|c|c|c|c|c|c|}
\hline \multirow[b]{2}{*}{ Study or Subgroup } & \multicolumn{2}{|c|}{ Prone } & \multicolumn{2}{|c|}{ Supine } & \multirow[b]{2}{*}{ Weight } & \multirow{2}{*}{$\begin{array}{c}\text { Risk Ratio } \\
\text { IV, Random, 95\% }\end{array}$} \\
\hline & Events & Total & Events & Total & & \\
\hline \multicolumn{7}{|c|}{ Moderate to Severe ARDS } \\
\hline Mancebo et al. 2006 & 38 & 76 & 37 & 60 & $17.0 \%$ & $0.81[0.60,1.10]$ \\
\hline Chan et al. 2007 & 4 & 11 & 4 & 11 & & 3.02] \\
\hline Fernandez et al. 2008 & 8 & 21 & 10 & 19 & $6.9 \%$ & $6,1.45]$ \\
\hline Taccone et al. 2009 & 52 & 168 & 57 & 174 & $16.6 \%$ & $9,1.29]$ \\
\hline Guerin et al. 2013 & 38 & 237 & 75 & 229 & $15.3 \%$ & $0.49[0.35,0.69]$ \\
\hline Subtotal $(95 \% \mathrm{Cl})$ & & 513 & & 493 & $59.1 \%$ & $0.74[0.56,0.99]$ \\
\hline \multicolumn{7}{|c|}{$\begin{array}{l}\text { Total events } \quad 140 \quad 183 \\
\text { Heterogeneity: } \mathrm{Tau}^{2}=0.05 ; \mathrm{Chi}^{2}=8.51, \mathrm{df}=4(\mathrm{P}=0.07) ; I^{2}=53 \% \\
\text { Test for overall effect: } \mathrm{Z}=2.06(\mathrm{P}=0.04)\end{array}$} \\
\hline \multicolumn{7}{|l|}{ All ARDS } \\
\hline Gattinoni et al. 2001 & 70 & 152 & 67 & 152 & $19.1 \%$ & $1.04[0.8$ \\
\hline et al. 2004 & 134 & 413 & 119 & 378 & $20.9 \%$ & 1.0 \\
\hline Voggenreiter et al. 2005 & 1 & 21 & 3 & 19 & $0.9 \%$ & $3,2.66$ \\
\hline Subtotal $(95 \% \mathrm{Cl})$ & & 586 & & 549 & $40.9 \%$ & $1.03[0.88,1.20]$ \\
\hline Total events & 205 & & 189 & & & \\
\hline \multicolumn{7}{|c|}{$\begin{array}{l}\text { Heterogeneity: } \mathrm{Tau}^{2}=0.00 ; \mathrm{Chi}^{2}=1.24, \mathrm{df}=2(\mathrm{P}=0.54) ; I^{2}=0 \% \\
\text { Test for overall effect: } Z=0.36(\mathrm{P}=0.72)\end{array}$} \\
\hline Total $(95 \% \mathrm{Cl})$ & & 1099 & & 1042 & $100.0 \%$ & $0.84[0.68,1.04$ \\
\hline Total events & 345 & & 372 & & & \\
\hline \multicolumn{7}{|c|}{$\begin{array}{l}\text { Heterogeneity: } \mathrm{Tau}^{2}=0.04 ; \mathrm{Chi}^{2}=16.94, \mathrm{df}=7(\mathrm{P}=0.02) ; I^{2}=59 \% \\
\text { Test for overall effect: } \mathrm{Z}=1.60(\mathrm{P}=0.11)\end{array}$} \\
\hline Test for subgroup diffe & nces: & 0 & & & 2 & \\
\hline
\end{tabular}

Figure 4. Primary outcome: mortality; subgroup analysis according to study entry criteria of moderate to severe acute respiratory distress syndrome (ARDS) versus all ARDS. Forest plot demonstrating pooled data of early mortality in studies of moderate to severe ARDS versus studies enrolling all types of ARDS using a random effects model. Early mortality was defined as 28-day mortality used for all studies where available; for Gattinoni and colleagues (4), 30-day mortality was used, for Voggenreiter and colleagues (6), 90-day mortality was used, for Fernandez and colleagues (22), 60-day mortality was used, and for Mancebo and colleagues (19), in-hospital mortality was used. The arrowhead indicates that the lower confidence interval is beyond the $x$-axis of the graph. $\mathrm{Cl}=\mathrm{confidence} \mathrm{interval;}$;f $=$ degrees of freedom; Events = number of deaths; $P=$ statistical heterogeneity; $\mathrm{IV}=$ inverse variance; Total = total number of patients.

positioning (Appendix E4). However, there were increased risks of endotracheal tube obstruction (RR, 1.76; 95\% CI, 1.24-2.50; $I^{2}, 26 \%$; three studies $\left.[5,20,21]\right)$ and pressure sores (RR, 1.22; 95\% CI, 1.06-1.41; $I^{2}, 0 \%$; three studies $\left.[4,5,23]\right)$ with prone positioning (Appendix E4).

\section{Discussion}

Our systematic review and meta-analysis pooled results from eight randomized trials conducted over 12 years. Although the primary meta-analysis did not demonstrate a mortality difference, a priori subgroup analyses demonstrated lower mortality when prone positioning was applied for 12 hours or longer per day and in studies including moderate to severe ARDS. Given, however, that the within-trial subgroup analysis of severe ARDS versus mild to moderate ARDS did not demonstrate a statistically significant difference between the two subgroups, despite there being a mortality benefit with severe ARDS
(Appendix E4), the specific $\mathrm{Pa}_{\mathrm{O}_{2}} / \mathrm{F}_{\mathrm{O}_{2}}$ threshold at which one might benefit from prone positioning is not entirely clear. The trials also facilitated meta-analyses of important complications of prone positioning, which revealed an increase in endotracheal tube obstruction and pressure sores.

The evolution of the evidence for prone positioning demonstrates how the benefit of an important and effective adjuvant therapy may not be obvious until applied in the optimal manner and to the right population. Our findings highlight the importance of identifying a responsive target population and mastering the specifics of the intervention's execution.

Prone positioning appears to benefit more hypoxemic patients with ARDS, and particularly when applied for a longer daily duration. Those with the most severe lung injury have the greatest physiologic rationale for benefits from prone positioning, due to more severe and heterogeneous lung injury and greater ventilation-perfusion heterogeneity in the dependent lung zones while supine. Placing a patient in the prone position facilitates recruitment and decreases heterogeneity of compliance, which improves oxygenation and minimizes injurious ventilation (24). Application of prone positioning yielded the greatest benefit in studies in which it was applied for 12 hours or longer per day. This is not surprising, as a decrease in ventilator-induced lung injury is likely the mechanism by which prone positioning decreases mortality, and longer periods of prone ventilation means less injury (21). As such, prone positioning could be perceived as a treatment to be initiated early, at the appropriate severity of ARDS, and at the correct dose $(\geqslant 12 \mathrm{~h})$. Three systematic reviews and study-level meta-analyses (24-26) have been published since the most recent RCT. Lee and colleagues (25) included 11 RCTs, 3 of which we excluded. They found that prone positioning significantly reduced mortality (odds ratio, 0.77; 95\% CI, 0.59-0.99; $P, 0.039 ; I^{2}, 33.7 \%$ ). The difference in results may arise from the time point of the mortality assessment (their 
trial included mortality at the longestavailable follow-up) or differences in trial selection (one trial did not focus primarily on ARDS [15] and two trials combined prone positioning with high-frequency oscillation $[27,28])$. Sud and colleagues (7) included 11 trials and found a significantly reduced mortality favoring prone positioning in the cohort of studies with reduced tidal volume (RR, 0.74, 95\% CI, 0.59-0.95; $I^{2}, 29 \%$ ). The difference found in their results can be attributed to three additional studies (Appendix E3) $(16,18,27)$, and the fact that the mortality time point chosen was obtained at the longest period of follow-up. Contrary to our review, which chose the earlier mortality time point ( $28 \mathrm{~d}$ ), obtaining data from the longest period of follow-up is a reasonable alternative approach for pooling mortality data.

Our review is unique in that we established, a priori, a series of important subgroup analyses to reflect contemporary application of prone positioning. The large number of studies allowed us to conduct meta-analyses of adverse events. It is important to highlight several limitations to our review. Given the evolution of the target population (progressively more severe ARDS) and the longer duration of prone positioning, our primary analysis captured three studies that included outdated approaches to prone positioning, given their short duration in the prone position (4-6). We did not restrict our inclusion criteria to more contemporary trials; therefore, we were limited in our ability to address which features conferred the greatest benefit (i.e., lung-protective ventilation, duration of time prone, and restriction of entry to patients with moderate to severe ARDS); however, we attempted to capture this during our subgroup analyses. Including the entire body of evidence facilitated an extensive exploration of important adverse events. Although we found that daily duration of proning of at least 12 hours reduced mortality, the exact threshold required to confer benefit remains unknown. Finally, the hypoxemia threshold at which prone positioning is beneficial has not been definitively established. Although the metaanalysis of trials of moderate to severe ARDS (i.e., $\mathrm{Pa}_{\mathrm{O}_{2}} / \mathrm{FI}_{\mathrm{O}_{2}}<200$ ) demonstrated reduced mortality, the more recent trial by Guérin and colleagues (21) included patients with a $\mathrm{Pa}_{\mathrm{O}_{2}} / \mathrm{FI}_{\mathrm{O}_{2}}$ ratio of 150 or less. Within-trial subgroup data based on this threshold were not available from all studies to establish the validity of this threshold among all trials. Finally, despite the numerous subgroup analyses, it was not possible to definitively address the potential collinearity that arises between duration of time prone and lung-protective ventilation, as well as duration of time prone and severity of illness. Although, for the former, we performed post hoc analyses (Appendix E5), this was limited in that the comparator groups were single studies, and we therefore interpret these results with caution. With regard to collinearity that may exist between duration of time prone and severity of illness, we attempted to explore this through the study-level subgroup analysis; however, an individual patient-level meta-analysis would be the optimal approach to exploring this potential collinearity.

\section{Conclusions}

In our systematic review of eight randomized trials evaluating prone positioning compared with supine positioning for adults undergoing mechanical ventilation, we found a reduction in mortality when the prone position is used in patients with moderate to severe ARDS $\left(\mathrm{Pa}_{\mathrm{O}_{2}} / \mathrm{FI}_{\mathrm{O}_{2}}<200\right)$ and for a longer duration $(\geqslant 12 \mathrm{~h})$. Prone positioning is not without harm, however, and is associated with an increased risk of endotracheal tube obstruction and pressure sores.

Author disclosures are available with the text of this article at www.atsjournals.org.

\section{References}

1 Piehl MA, Brown RS. Use of extreme position changes in acute respiratory failure. Crit Care Med 1976;4:13-14.

2 Pappert D, Rossaint R, Slama K, Grüning T, Falke KJ. Influence of positioning on ventilation-perfusion relationships in severe adult respiratory distress syndrome. Chest 1994;106:1511-1516.

3 Douglas WW, Rehder K, Beynen FM, Sessler AD, Marsh HM. Improved oxygenation in patients with acute respiratory failure: the prone position. Am Rev Respir Dis 1977;115:559-566.

4 Gattinoni L, Tognoni G, Pesenti A, Taccone P, Mascheroni D, Labarta V, Malacrida R, Di Giulio P, Fumagalli R, Pelosi P, et al.; Prone-Supine Study Group. Effect of prone positioning on the survival of patients with acute respiratory failure. N Engl J Med 2001;345:568-573.

5 Guerin C, Gaillard S, Lemasson S, Ayzac L, Girard R, Beuret P, Palmier B, Le QV, Sirodot M, Rosselli S, et al. Effects of systematic prone positioning in hypoxemic acute respiratory failure: a randomized controlled trial. JAMA 2004;292:2379-2387.

6 Voggenreiter G, Aufmkolk M, Stiletto RJ, Baacke MG, Waydhas C, Ose C, Bock E, Gotzen L, Obertacke U, Nast-Kolb D. Prone positioning improves oxygenation in post-traumatic lung injury-a prospective randomized trial. J Trauma 2005;59:333-341. [Discussion, pp. 341-343.]

7 Sud S, Friedrich JO, Taccone P, Polli F, Adhikari NK, Latini R, Pesenti A, Guérin C, Mancebo J, Curley MA, et al. Prone ventilation reduces mortality in patients with acute respiratory failure and severe hypoxemia: systematic review and meta-analysis. Intensive Care Med 2010;36:585-599.
8 Abroug F, Ouanes-Besbes L, Dachraoui F, Ouanes I, Brochard L. An updated study-level meta-analysis of randomised controlled trials on proning in ARDS and acute lung injury. Crit Care 2011;15:R6-R15.

9 Ranieri VM, Rubenfeld GD, Thompson BT, Ferguson ND, Caldwell E, Fan E, Camporota L, Slutsky AS; ARDS Definition Task Force. Acute respiratory distress syndrome: the Berlin definition. JAMA 2012;307:2526-2533.

10 Higgins JP, Altman DG, Gøtzsche PC, Jüni P, Moher D, Oxman AD, Savovic J, Schulz KF, Weeks L, Sterne JA; Cochrane Bias Methods Group; Cochrane Statistical Methods Group. The Cochrane Collaboration's tool for assessing risk of bias in randomised trials. BMJ 2011;343:d5928.

11 Balshem H, Helfand M, Schünemann HJ, Oxman AD, Kunz R, Brozek J, Vist GE, Falck-Ytter Y, Meerpohl J, Norris S, et al. GRADE guidelines: 3. Rating the quality of evidence. J Clin Epidemiol 2011;64:401-406.

12 Guyatt GH, Oxman AD, Santesso N, Helfand M, Vist G, Kunz R, Brozek J, Norris S, Meerpohl J, Djulbegovic B, et al. GRADE guidelines: 12. Preparing summary of findings tables-binary outcomes. J Clin Epidemiol 2013;66:158-172.

13 DerSimonian R, Laird N. Meta-analysis in clinical trials. Control Clin Trials 1986;7:177-188.

14 Higgins JP, Thompson SG, Deeks JJ, Altman DG. Measuring inconsistency in meta-analyses. BMJ 2003;327:557-560.

15 Brower RG, Matthay MA, Morris A, Schoenfeld D, Thompson BT, Wheeler A; Acute Respiratory Distress Syndrome Network. Ventilation with lower tidal volumes as compared with traditional tidal volumes for acute lung injury and the acute respiratory distress syndrome. N Engl J Med 2000;342:1301-1308. 
16 Beuret P, Carton MJ, Nourdine K, Kaaki M, Tramoni G, Ducreux JC. Prone position as prevention of lung injury in comatose patients: a prospective, randomized, controlled study. Intensive Care Med 2002; 28:564-569.

17 Curley MA, Hibberd PL, Fineman LD, Wypij D, Shih MC, Thompson JE, Grant MJ, Barr FE, Cvijanovich NZ, Sorce L, et al. Effect of prone positioning on clinical outcomes in children with acute lung injury: a randomized controlled trial. JAMA 2005;294:229-237.

18 Watanabe I, Fujihara H, Sato K, Honda T, Ohashi S, Endoh H, Yamakura T, Taga K, Shimoji K. Beneficial effect of a prone position for patients with hypoxemia after transthoracic esophagectomy. Crit Care Med 2002;30:1799-1802.

19 Mancebo J, Fernández R, Blanch L, Rialp G, Gordo F, Ferrer M, Rodríguez F, Garro P, Ricart P, Vallverdú I, et al. A multicenter trial of prolonged prone ventilation in severe acute respiratory distress syndrome. Am J Respir Crit Care Med 2006;173: 1233-1239.

20 Taccone P, Pesenti A, Latini R, Polli F, Vagginelli F, Mietto C, Caspani L, Raimondi F, Bordone G, lapichino G, et al.; Prone-Supine II Study Group. Prone positioning in patients with moderate and severe acute respiratory distress syndrome: a randomized controlled trial. JAMA 2009;302:1977-1984.

21 Guérin C, Reignier J, Richard J-C, Beuret P, Gacouin A, Boulain T, Mercier E, Badet M, Mercat A, Baudin O, et al.; PROSEVA Study Group. Prone positioning in severe acute respiratory distress syndrome. N Engl J Med 2013;368:2159-2168.
22 Fernandez R, Trenchs X, Klamburg J, Castedo J, Serrano JM, Besso G, Tirapu JP, Santos A, Mas A, Parraga M, et al. Prone positioning in acute respiratory distress syndrome: a multicenter randomized clinical trial. Intensive Care Med 2008;34:1487-1491.

23 Chan MC, Hsu JY, Liu HH, Lee YL, Pong SC, Chang LY, Kuo BI, Wu CL. Effects of prone position on inflammatory markers in patients with ARDS due to community-acquired pneumonia. J Formos Med Assoc 2007;106:708-716.

24 Gattinoni L, Marini JJ, Pesenti A, Quintel M, Mancebo J, Brochard L. The "baby lung" became an adult. Intensive Care Med 2016;42:663-673.

25 Lee JM, Bae W, Lee YJ, Cho YJ. The efficacy and safety of prone positional ventilation in acute respiratory distress syndrome: updated study-level meta-analysis of 11 randomized controlled trials. Crit Care Med 2014;42:1252-1262.

26 Beitler JR, Shaefi S, Montesi SB, Devlin A, Loring SH, Talmor D, Malhotra A. Prone positioning reduces mortality from acute respiratory distress syndrome in the low tidal volume era: a metaanalysis. Intensive Care Med 2014;40:332-341.

27 Demory D, Michelet P, Arnal JM, Donati S, Forel JM, Gainnier M, Brégeon F, Papazian L. High-frequency oscillatory ventilation following prone positioning prevents a further impairment in oxygenation. Crit Care Med 2007;35:106-111.

28 Papazian L, Gainnier M, Marin V, Donati S, Arnal JM, Demory D, Roch A, Forel JM, Bongrand $\mathrm{P}$, Brégeon $\mathrm{F}$, et al. Comparison of prone positioning and high-frequency oscillatory ventilation in patients with acute respiratory distress syndrome. Crit Care Med 2005;33:2162-2171. 